\title{
Correlation of inflammatory and proangiogenic cytokines from undiluted vitreous samples with spectral domain OCT scans, in untreated branch retinal vein occlusion
}

\author{
Marcel Pfister ${ }^{1,4}$ \\ Florian Rothweiler ${ }^{2}$ \\ Martin Michaelis ${ }^{2}$ \\ Jindrich Cinatl J ${ }^{2}$ \\ Ralf Schubert ${ }^{3}$ \\ Frank H Koch' \\ Michael J Koss ${ }^{1,4}$ \\ 'Department of Ophthalmology, \\ Goethe University, Frankfurt, \\ Germany; ${ }^{2}$ Department of \\ Virology, Goethe University, \\ Frankfurt, Germany; ${ }^{3}$ Department \\ of Pediatric Pulmonology, Allergy and \\ Cystic Fibrosis, Children's Hospital, \\ Goethe University, Frankfurt, \\ Germany; ${ }^{4}$ Doheny Eye Institute, \\ University of Southern California, \\ Los Angeles, CA, USA
}

\author{
This article was published in the following Dove Press journal: \\ Clinical Ophthalmology \\ 3I May 2013 \\ Number of times this article has been viewed
}

\begin{abstract}
Purpose: To assess the levels of inflammatory and angiogenic cytokines in undiluted vitreous from treatment-naïve patients with macular edema secondary to nonischemic branch retinal vein occlusion (BRVO), with flow cytometric bead array (CBA) and to correlate the results with subjective and multiple spectral-domain optical coherence tomography (SD-OCT) parameters.

Methods: A total of 43 eyes from 43 patients (mean age 69.7 years, 23 male) were divided into groups of new, "fresh" ( $\mathrm{n}=28$; mean duration after onset 4.1 months) and older BRVO ( $\mathrm{n}=15$; 11.6 months). Because of macular edema, these patients underwent an intravitreal therapy combining a single-site $23 \mathrm{~g}$ core vitrectomy with bevacizumab and dexamethasone. Undiluted vitreous was then analyzed for interleukin-6 (IL-6), monocyte chemoattractant protein-1 (MCP-1), and vascular endothelial growth factor isoform A (VEGF-A) levels with CBA and correlated with visual acuity (VA), clinical parameters of BRVO (type and perfusion status), and morphologic parameters, such as central macular thickness, central retinal thickness, thickness of the neurosensory retina, thickness of the serous retinal detachment, and the disruption of the ellipsoid line (photoreceptor inner and outer segments) and the external limiting membrane, as measured with SD-OCT. Twenty-eight undiluted vitreous samples from patients with idiopathic, nonuveitis vitreous floaters served as the controls.
\end{abstract}

Results: The mean IL-6 was $23.2 \mathrm{pg} / \mathrm{mL}$ (standard deviation, \pm 48.8 ), MCP-1 was 602.6 ( \pm 490.3 ), and VEGF-A was $161.8( \pm 314.3)$, and this was higher than in the control group, which had a mean IL-6 of $6.2 \pm 3.4 \mathrm{pg} / \mathrm{mL}(P=0.17), \mathrm{MCP}-1$ of $253.2 \pm 73.5(P<0.0000001)$, and VEGF-A of $7.0 \pm 4.9(P<0.003)$. In all BRVO samples, IL-6 correlated positively with MCP-1 and VEGF-A (correlation coefficient $\mathrm{r}=0.79$ and $\mathrm{r}=0.46$, respectively). VEGF-A was the only cytokine to correlate significantly with SD-OCT parameters (thickness of the neurosensory retina $\mathrm{r}=0.31$; disruption of the ellipsoid line $r=0.33$ ). In the older BRVO group, there was a positive correlation between cytokines (IL-6 with MCP-1, $r=0.77$; Il-6 with VEGF-A, $r=0.68$; MCP-1 and VEGF-A, $r=0.68)$, whereas only IL-6 correlated with MCP-1 in the fresh group $(r=0.8)$.

Conclusion: The inflammatory markers and VEGF-A were elevated in the vitreous fluid of patients with BRVO, and these correlated with one another. VEGF-A was more often correlated with the morphologic changes assessed by SD-OCT, whereas the inflammatory markers had no significant influence on SD-OCT changes.

Keywords: vitreous samples, BRVO, VEGF, MCP, IL-6, CBA, SD-OCT

Correspondence: Marcel Pfister

Department of Ophthalmology, Hospital of the Goethe University,

Frankfurt am Main, Theodor Stern Kai 7, 60590 Frankfurt am Main, Germany

Tel +496963015649

Fax +496963015621

Email marcel.pfister@kgu.de

\section{Introduction}

Today, we can assess patients with branch retinal vein occlusion (BRVO) not only for the assessment of changes in central macular thickness (CMT), but also, to conduct 
a detailed analysis of the neurosensory retinal layers. The prognosis for visual acuity (VA) can be based upon the integrity of the ellipsoid line (EL) (photoreceptor inner and outer segments) and the external limiting membrane (ELM), which are important landmarks for good VA rehabilitation. ${ }^{1}$ The development of subfoveal serous detachment seems to be a potential negative clinical indicator. ${ }^{2,3}$ In terms of reducing the need for frequent intravitreal reinjections, careful spectral-domain optical coherence tomography (SD-OCT) analysis also allows for flexible anti-vascular endothelial growth factor (VEGF) treatment, which has demonstrated significant functional and anatomic changes. ${ }^{4,5}$

Macular edema (ME) secondary to BRVO occurs after multifactorial pathophysiologic changes that affect intraocular cytokine levels. Cytokines mediate between endothelial cells and inflammatory cells, which themselves interact with cytokine expression. ${ }^{6,7}$ The prolonged contact of endothelial cells with proinflammatory cytokines might promote more thrombosis, on top of the initial venous occlusion. Upregulated VEGF is a known chemoattractant cytokine for macrophages and leukocytes and thus plays an important role in the pathophysiologic imbalance of BRVO. ${ }^{8}$

Funk et $\mathrm{al}^{5}$ demonstrated that anti-VEGF monotherapy has an impact on the expression of VEGF and on inflammatory markers, including interleukin-6 (IL-6) and monocyte chemoattractant protein 1 (MCP-1), in anterior chamber taps. ${ }^{5}$ IL-6 is a major promoter of most acute-phase proteins. It mediates the change from acute to chronic inflammation and thus combines the inflammatory process with angiogenesis. ${ }^{9}$ In central retinal vein occlusion (CRVO), Noma et al ${ }^{10}$ was able to demonstrate that the severity of $\mathrm{ME}$ is correlated with cytokine imbalance.

Using a combination therapy that involved a core vitrectomy, we were able to correlate cytokine levels from undiluted vitreous (before drug application) with the abovementioned detailed intraretinal layer changes assessed preoperatively with SD-OCT. ${ }^{11}$ In this study, we aimed to achieve a better understanding of the BRVO pathophysiology and of the predictive value of SD-OCT examinations.

\section{Methods}

This study was conducted after local institutional review board (IRB) approval. Following the protocol of the sixth revision of the Declaration of Helsinki, each participating patient consented to the study.
Patients were included in the study if they had a BRVOassociated clinically significant ME (CSME) involving the fovea but a macular thickness of not more than $1000 \mu \mathrm{m}$, which led to a VA of not worse than 2.0 logarithm of the minimum angle of resolution (logMAR). Excluded patients were patients with BRVO-associated complications, such as iris rubeosis or neovascularization. We additionally excluded patients with a history of previous intravitreal drug injections or surgery.

The Early Treatment Diabetic Retinopathy Study (ETDRS) best-corrected VA (BCVA) was assessed at $5 \mathrm{~m}$, with stopping at three out of five optotypes, and was expressed as the logMAR.

SD-OCT (3D OCT-2000; Topcon Corp, Tokyo, Japan) was used, acquiring a scan depth of $2.3 \mathrm{~mm}$ with a horizontal resolution of $20 \mu \mathrm{m}$ and a longitudinal resolution of 5-6 $\mu \mathrm{m}$, at an amplitude modulation scan (A-scan) speed of $27.000 \mathrm{~A}$ scans/second.

Consecutive sections, and vertical and horizontal scans within the macular region were obtained by a well-trained OCT-certified (Vienna Reading Center, Vienna, Austria) technician. Using OCT images, a standardized reading protocol was performed on the OCT scans, with a quality score over $16 \mathrm{~dB}$, including the following six measurements (Figure 1):

1. CMT, calculated as the distance of the inner limiting membrane to the basal membrane of the retinal pigment epithelium, including all the compartments in between

2. Total retinal thickness (TRT), defined as the biggest distance of the inner limiting membrane to the basal membrane of the RPE, within the three-dimensional (3D) scan field (127 A-scans)

3. The thickness of the neurosensory retina (TNeuro)

4. The subfoveal serous retinal thickness (SRT)

5. The disruption of the inner and outer photoreceptor segments (dEL)

6. The disruption of the external limiting membrane (dELM), at the foveal region.

These measurements were reviewed, with a caliper that was built into the software of the OCT machine, by two retina specialists $(\mathrm{MK} / \mathrm{FK})$ who were blinded to the VA results and the results of the cytokine evaluation. The intergrader reliability $(\kappa)$ was assessed with a $\kappa$-value of 0.88 to 0.95 . Additionally, the A-scans were evaluated for the occurrence of intraretinal cysts or hyper-reflective spots. To exclude false positive findings of dEL or of dELM sections due to overlying cystic edema or intraretinal bleeding, the A-scans were 


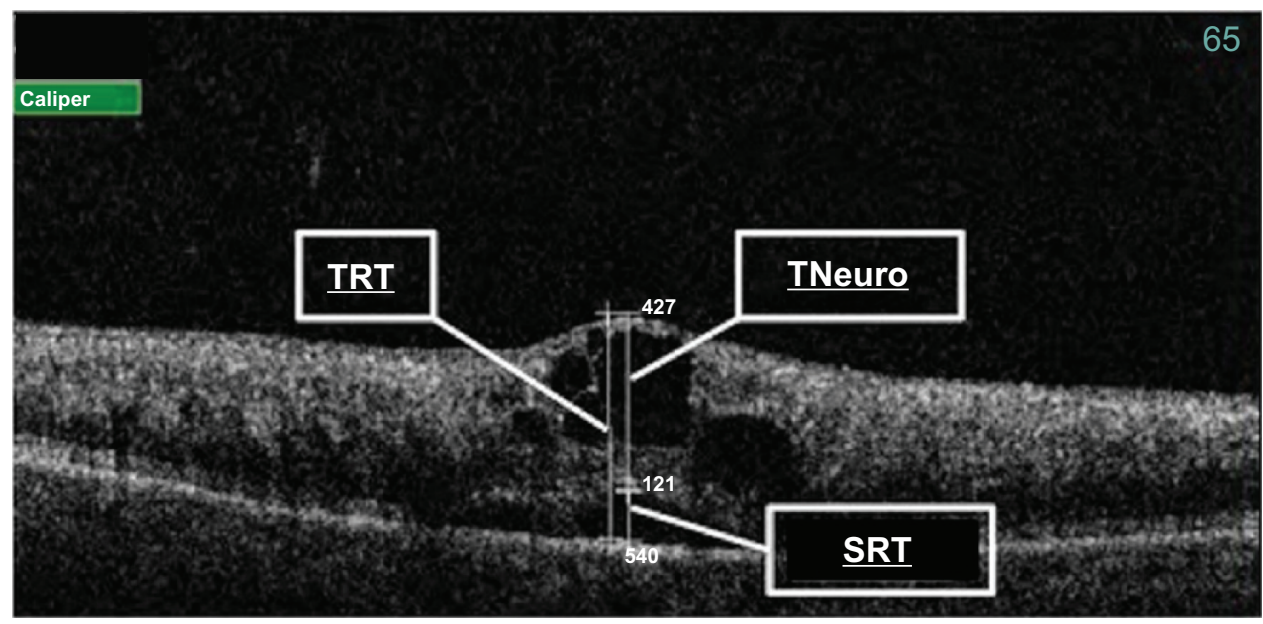

Figure I Cystoid macular edema secondary to a "fresh" BRVO, with marked TRT, TNeuro, and SRT, as seen in SD-OCT.

Note: Thickness was measured in $\mu \mathrm{m}$.

Abbreviations: BRVO, branch retinal vein occlusion; SD-OCT, spectral-domain optical coherence tomography; SRT, subfoveal serous retinal thickness; TNeuro, thickness of the neurosensory retina; TRT, total retinal thickness.

scrolled through the macular region. Ischemic retinopathy was declared with $>$ ten disc areas of nonperfusion by fluorescein angiography, using the OIS WinStation $11 \mathrm{~K}^{\mathrm{TM}}$ (Ophthalmic Imaging Systems, Inc, Sacramento, CA, USA). In cases of an early, "fresh" BRVO with extensive hemorrhage blocking the retinal parts, the fluorescein angiography was delayed until the bleeding cleared up.

The surgical technique that yielded the sample collection was described in a separate report. ${ }^{12}$ Briefly, 0.6 to $0.8 \mathrm{~mL}$ of undiluted vitreous fluid from the mid- to posterior vitreous cavity were extracted by an assistant, under the guidance of the surgeon who controlled the vitrector (Insight Instruments, Inc. Stuart, FL, USA) with a headset and a magnifying 28-diopter lens.

Samples taken from an idiopathic, nonuveitic floaterectomy served as the controls. All samples were saved prior to drug application and frozen at $-80^{\circ} \mathrm{C}$.

The Cytometric Bead Array (CBA) Flex Set System (BD Biosciences, Heidelberg, Germany) was used to determine the IL-6, MCP-1, and VEGF-A, according to the manufacturer's instruction manual, including the measurement on a FACSArray ${ }^{\mathrm{TM}}$ Bioanalyzer (BD Biosciences) with FCAP Array $^{\mathrm{TM}}$ v3.01 software (Soft Flow Hungary Ltd, Pécs, Hungary). The data were saved in EXCEL ${ }^{\circledR}$ (Microsoft Office 2010; Microsoft Corp, Redmond, WA, USA) and statistically analyzed with $\mathrm{BiAS}^{\circledR}$ software v8.3.8 (Epsilon, Darmstadt, Germany). The data had a nonparametric distribution, which was checked with the David's test (error level of 5\%); thus the Wilcoxon-Mann-Whitney test could be applied with a $P$-value of $<0.05$.
The Spearman rank correlation coefficient was used to examine the relationship between the influence of the cytokines on the other parameters, such as changes in SD-OCT.

\section{Results \\ Patients}

The BRVO group (23 men and 20 women) was aged $69.7 \pm 12.9$ years (mean \pm standard deviation [SD]), and the control group (12 men and 16 women) was aged $66.2 \pm 7.9$ years $(P=0.91$ and 0.32 , respectively) (Table 1$)$.

Table I Epidemiological data

\begin{tabular}{llll}
\hline & $\begin{array}{l}\text { BRVO } \\
\text { N }=\mathbf{4 3}\end{array}$ & Control & P-value \\
& 43 & 28 & \\
Male/female & $23 / 20$ & $12 / 16$ & 0.91 \\
Age in years & $69.7 \pm 12.9$ & $66.2 \pm 7.9$ & 0.32 \\
Blood pressure* & & & \\
$\quad$ Systolic & $144 \pm 17$ & $121 \pm 10$ & $<0.01$ \\
$\quad$ Diastolic & $82 \pm 17$ & $75 \pm 8$ & 0.08 \\
Hypertension & 33 & 5 & $<0.001$ \\
Drug therapy & 21 & 3 & 0.004 \\
VA in logMAR & $0.85 \pm 0.5 \mathrm{I}$ & $0.5 \mathrm{I} \pm 0.22$ & $<0.002$ \\
Duration of BRVO** & $6.7 \pm 4.0$ & & \\
Type & Fresh & Older & \\
\hline BRVO & & & \\
$\quad \mathrm{N}$ & 28 & 15 & $<0.01$ \\
$\quad$ Duration of BRVO & $4.1 \pm 1.5$ & $1 \mathrm{I} .6 \pm 1.7$ & $<0.001$ \\
\hline
\end{tabular}

Notes: Values are expressed as mean ( \pm standard deviation). Differences are calculated using the Wilcoxon-Mann-Whitney test. *mmHg; **months.

Abbreviations: BRVO, branch retinal vein occlusion; logMAR, logarithm of the minimum angle of resolution; VA, visual acuity. 
The VA was $0.85 \pm 0.51 \log$ MAR in the BRVO group and $0.51 \pm 0.22$ in the control group $(P<0.002)$. The duration of the BRVO was $6.7 \pm 4.0$ months for all BRVO patients, and all were treatment naïve before the study start. The patients were distributed in a subgroup of fresh BRVO with a duration of $4.1 \pm 1.5$ months $(n=28)$ and a subgroup of old BRVO with a duration of $11.6 \pm 1.7$ months after the onset of the disease $(P<0.001)$, which was classified based upon the patients' subjective perception of symptoms. We defined a fresh BRVO as having a duration of less than 6 months.

\section{SD-OCT}

The mean absolute values $\pm \mathrm{SD}$ and the $95 \%$ confidence interval (CI) of the SD-OCT measurements are depicted in $\mu \mathrm{m}$ in Table 2. For all BRVO patients, the mean CMT was $459.5 \pm 144.1$ (CI 415.1-504.4 $\mu \mathrm{m}$ ), the TRT was $531.9 \pm 170.6$ (CI 479.1-584.3), the TNeuro was $430.9 \pm 101.6$ (CI 399.6-462.2), the SRT was $116.3 \pm 140$ (CI 73.2-159.4), the dEL was 2487.4 \pm 1385.7 (CI 2061-2914), and the dELM was 2892.6 \pm 1391.9 (CI 2464-3321). In 40 out of 43 patients $(93 \%)$, intraretinal cysts were noted, while in eight out of 43 patients (19\%), hyper-reflective spots occurred. For the subgroup with older BRVO, higher values were observed for all SD-OCT parameters aside from SRT in comparison with the fresh BRVO subgroup.

\section{Correlation of SD-OCT}

The CMT correlated significantly with TRT $(r=0.83)$, with SRT $(r=0.58)$, with dEL $(r=0.58)$, with dELM $(r=0.48)$, and with intraretinal cysts $(r=0.36)$. TRT correlated significantly with TNeuro $(r=0.42)$, with SRT $(r=0.61)$, with dEL $(r=0.71)$, and with dELM $(r=0.64)$, and with intraretinal cysts $(\mathrm{r}=0.35)$. TNeuro and SRT correlated significantly with dEL ( $\mathrm{r}=0.39$ and 0.66 , respectively), with dELM ( $\mathrm{r}=0.40$ and 0.59 , respectively), and with intraretinal cysts $(r=0.42$ and 0.30 , respectively). $d E L$ and dELM correlated significantly with one another $(r=0.90)$. In total, TRT correlated with six; CMT, SRT, dEL, and dELM correlated with five; and TNeuro and intraretinal cysts correlated with four SD-OCT parameters.

In the fresh BRVO group, there were more significant correlations among the SD-OCT parameters than were in

Table 2 Characteristics of the SD-OCT measurements

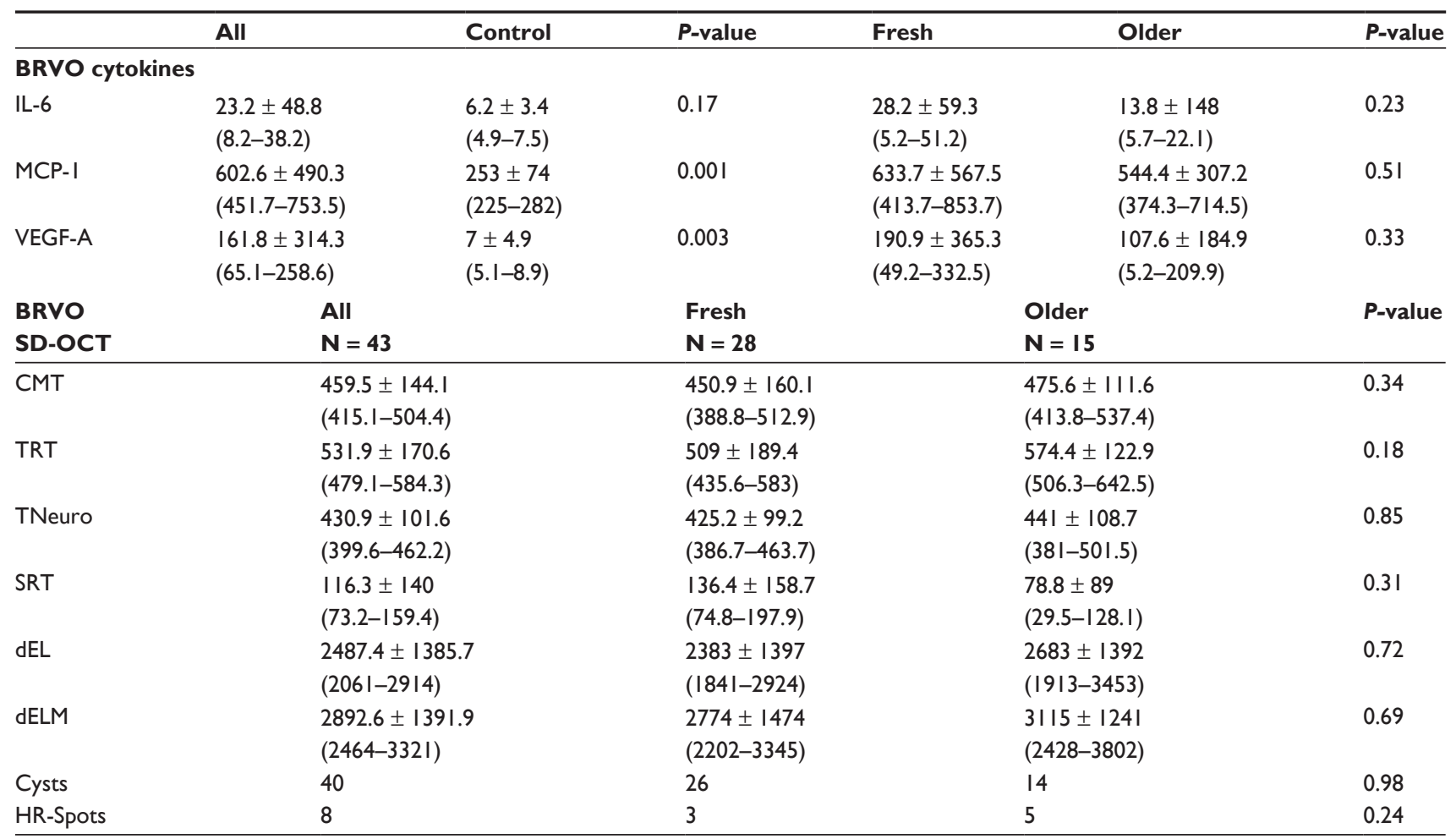

Notes: The absolute mean values of the vitreous cytokines are in $\mathrm{pg} / \mathrm{mL}$. All measurements are depicted as mean values \pm SD in $\mu \mathrm{m}$. The $95 \%$ confidence interval values are depicted in brackets.

Abbreviations: BRVO, branch retinal vein occlusion; CMT, central macular thickness; Cysts, intraretinal cysts; dEL, disruption of the inner and outer photoreceptor segments; dELM, disruption of the external limiting membrane; HR-spots, hyperreflective spots; IL-6, interleukin-6; MCP-I, monocyte chemoattractant protein-I; SD, standard deviation; SD-OCT, spectral-domain optical coherence tomography; SRT, subfoveal serous retinal thickness; TNeuro, thickness of the neurosensory retina; TRT, total retinal thickness; VEGF-A, vascular endothelial growth factor-A. 
the older BRVO group (15 versus five) (Table 3). In the fresh group, CMT correlated significantly with TRT $(r=0.79)$, with SRT $(r=0.65)$, and with dEL $(r=0.68)$ and with dELM $(\mathrm{r}=0.57)$. TRT correlated significantly with SRT $(\mathrm{r}=0.63)$, with dEL $(r=0.77)$, and with dELM $(r=0.71)$. TNeuro and SRT correlated significantly with dEL $(0.48$ and 0.68 , respectively), with dELM ( $\mathrm{r}=0.47$ and 0.64 , respectively), and TNeuro, was also correlated significantly with cysts $(\mathrm{r}=0.43)$. dEL and dELM correlated significantly with one another $(\mathrm{r}=0.90)$. Intraretinal cysts correlated with $\mathrm{dEL}$ and dELM (both had $\mathrm{r}=43$ ). In total, dEL and dELM correlated with six; CMT and TRT correlated with four; and TNeuro, SRT, and intraretinal cysts correlated with three SD-OCT parameters. In the old BRVO group, TRT correlated with CMT and TRT ( $\mathrm{r}=0.81$ and 0.76 , respectively), and SRT correlated with CMT and dEL $(r=0.66$ and 0.52, respectively). $d E L$ and $d / E L M$ correlated with $r=0.91$.

\section{Vitreal cytokine levels}

The mean vitreal IL-6, MCP-1, and VEGF-A levels can be found in Table 2 .

\section{Correlation between cytokines}

All cytokines were positively correlated with one another. IL-6 was positively correlated (Table 4 ) with both MCP-1 $(\mathrm{r}=0.79 ; P<0.0001)$ and VEGF-A $(\mathrm{r}=0.46 ; P<0.0001)$; MCP-1 was correlated with VEGF-A $(\mathrm{r}=0.42 ; P<0.0001)$. This was also true in the fresh versus older BRVO subgroup analysis (Table 3), where the IL-6 level was correlated with MCP-1 (r = 0.77; $P<0.0001)$ and VEGF-A ( $\mathrm{r}=0.68$; $P<0.0001)$. MCP-1 levels were correlated with VEGF-A $(\mathrm{r}=0.68 ; P<0.006)$ in the older BRVO subgroup. In the fresh BRVO subgroup, there was a significant correlation among the inflammatory cytokines, IL-6 with MCP-1 $(\mathrm{r}=0.80 ; P<0.001)$.

\section{Correlation of cytokines and VA with SD-OCT}

VEGF-A was the only cytokine to correlate significantly with the SD-OCT parameters. It correlated with TNeuro $(\mathrm{r}=0.31$, $P<0.04)$ and with $\mathrm{dEL}(\mathrm{r}=0.33, P<0.03)$. In the subgroup analysis, there was a correlation seen in only the fresh BRVO group, where VEGF correlated significantly with TNeuro

Table 3 Spearman rank correlation matrix presenting the fresh BRVO subgroup (no shading) and the old BRVO subgroup (grey shading)

\begin{tabular}{|c|c|c|c|c|c|c|c|c|c|c|c|}
\hline $\begin{array}{l}\text { Fresh/ } \\
\text { old }\end{array}$ & VA & CMT & TRT & TNeuro & SRT & dEL & dELM & Cysts & IL-6 & MCP-I & VEGF-A \\
\hline VA & & $\begin{array}{l}0.30 \\
(0.12)\end{array}$ & $\begin{array}{l}0.25 \\
(0.19)\end{array}$ & $\begin{array}{l}0.28 \\
(0.14)\end{array}$ & $\begin{array}{l}0.49 * \\
(0.01)\end{array}$ & $\begin{array}{l}0.32 \\
(0.10)\end{array}$ & $\begin{array}{l}0.29 \\
(0.13)\end{array}$ & $\begin{array}{l}0.25 \\
(0.21)\end{array}$ & $\begin{array}{l}0.33 \\
(0.10)\end{array}$ & $\begin{array}{l}0.25 \\
(0.21)\end{array}$ & $\begin{array}{l}0.53^{*} \\
(0.004)\end{array}$ \\
\hline CMT & $\begin{array}{l}0.26 \\
(0.37)\end{array}$ & & $\begin{array}{l}0.79 * \\
(0.00 I)\end{array}$ & $\begin{array}{l}0.15 \\
(0.47)\end{array}$ & $\begin{array}{l}0.65^{*} \\
(0.00 \mathrm{I})\end{array}$ & $\begin{array}{l}0.68^{*} \\
(0.00 \mathrm{I})\end{array}$ & $\begin{array}{l}0.57^{*} \\
(0.002)\end{array}$ & $\begin{array}{l}0.33 \\
(0.10)\end{array}$ & $\begin{array}{l}0.07 \\
(0.73)\end{array}$ & $\begin{array}{r}-0.04 \\
(0.88)\end{array}$ & $\begin{array}{l}0.24 \\
(0.23)\end{array}$ \\
\hline TRT & $\begin{array}{l}0.40 \\
(0.1)\end{array}$ & $\begin{array}{l}0.8 I^{*} \\
(0.00 I)\end{array}$ & & $\begin{array}{l}0.38 \\
(0.05)\end{array}$ & $\begin{array}{l}0.63 * \\
(0.00 I)\end{array}$ & $\begin{array}{l}0.77^{*} \\
(0.00 \mathrm{I})\end{array}$ & $\begin{array}{l}0.7 I^{*} \\
(0.00 I)\end{array}$ & $\begin{array}{l}0.37 \\
(0.06)\end{array}$ & $\begin{array}{l}0.04 \\
(0.87)\end{array}$ & $\begin{array}{l}-0.06 \\
(0.75)\end{array}$ & $\begin{array}{l}0.33 \\
(0.09)\end{array}$ \\
\hline TNeuro & $\begin{array}{l}0.34 \\
(0.21)\end{array}$ & $\begin{array}{l}0.40 \\
(0.15)\end{array}$ & $\begin{array}{l}0.48 \\
(0.07)\end{array}$ & & $\begin{array}{l}0.13 \\
(0.49)\end{array}$ & $\begin{array}{l}0.48^{*} \\
(0.02)\end{array}$ & $\begin{array}{l}0.47^{*} \\
(0.01)\end{array}$ & $\begin{array}{l}0.43^{*} \\
(0.03)\end{array}$ & $\begin{array}{l}-0.02 \\
(0.91)\end{array}$ & $\begin{array}{l}0.24 \\
(0.23)\end{array}$ & $\begin{array}{l}0.37^{*} \\
(0.05)\end{array}$ \\
\hline SRT & $\begin{array}{l}0.35 \\
(0.2)\end{array}$ & $\begin{array}{l}0.66^{*} \\
(0.01)\end{array}$ & $\begin{array}{l}0.76^{*} \\
(0.001)\end{array}$ & $\begin{array}{l}0.21 \\
(0.44)\end{array}$ & & $\begin{array}{l}0.68^{*} \\
(0.00 \mathrm{I})\end{array}$ & $\begin{array}{l}0.64^{*} \\
(0.001)\end{array}$ & $\begin{array}{l}0.32 \\
(0.10)\end{array}$ & $\begin{array}{l}0.04 \\
(0.58)\end{array}$ & $\begin{array}{l}-0.15 \\
(0.44)\end{array}$ & $\begin{array}{l}0.23 \\
(0.25)\end{array}$ \\
\hline $\mathrm{dEL}$ & $\begin{array}{l}0.24 \\
(0.40)\end{array}$ & $\begin{array}{l}0.28 \\
(0.32)\end{array}$ & $\begin{array}{l}0.50 \\
(0.06)\end{array}$ & $\begin{array}{l}0.19 \\
(0.51)\end{array}$ & $\begin{array}{l}0.52 * \\
(0.05)\end{array}$ & & $\begin{array}{l}0.90^{*} \\
(0.001)\end{array}$ & $\begin{array}{l}0.43^{*} \\
(0.02)\end{array}$ & $\begin{array}{l}0.07 \\
(0.71)\end{array}$ & $\begin{array}{l}0.04 \\
(0.84)\end{array}$ & $\begin{array}{l}0.34 \\
(0.08)\end{array}$ \\
\hline dELM & $\begin{array}{l}0.40 \\
(0.15)\end{array}$ & $\begin{array}{l}0.24 \\
(0.38)\end{array}$ & $\begin{array}{l}0.42 \\
(0.13)\end{array}$ & $\begin{array}{l}0.09 \\
(0.76)\end{array}$ & $\begin{array}{l}0.50 \\
(0.56)\end{array}$ & $\begin{array}{l}0.91 * \\
(0.001)\end{array}$ & & $\begin{array}{l}0.43^{*} \\
(0.02)\end{array}$ & $\begin{array}{l}-0.03 \\
(0.90)\end{array}$ & $\begin{array}{l}-0.07 \\
(0.72)\end{array}$ & $\begin{array}{l}0.29 \\
(0.14)\end{array}$ \\
\hline Cysts & $\begin{array}{l}0.45 \\
(0.09)\end{array}$ & $\begin{array}{l}0.43 \\
(0.11)\end{array}$ & $\begin{array}{l}0.43 \\
(0.11)\end{array}$ & $\begin{array}{l}0.44 \\
(0.11)\end{array}$ & $\begin{array}{l}0.26 \\
(0.35)\end{array}$ & $\begin{array}{l}-0.25 \\
(0.37)\end{array}$ & $\begin{array}{l}-0.37 \\
(0.17)\end{array}$ & & $\begin{array}{l}-0.01 \\
(0.97)\end{array}$ & $\begin{array}{l}0.07 \\
(0.23)\end{array}$ & $\begin{array}{l}0.10 \\
(0.63)\end{array}$ \\
\hline IL-6 & $\begin{array}{l}0.36 \\
(0.19)\end{array}$ & $\begin{array}{l}-0.01 \\
(0.98)\end{array}$ & $\begin{array}{l}0.07 \\
(0.83)\end{array}$ & $\begin{array}{l}0.38 \\
(0.16)\end{array}$ & $\begin{array}{l}-0.29 \\
(0.30)\end{array}$ & $\begin{array}{l}0.32 \\
(0.26)\end{array}$ & $\begin{array}{l}0.27 \\
(0.35)\end{array}$ & $\begin{array}{l}0.06 \\
(0.83)\end{array}$ & & $\begin{array}{l}0.80^{*} \\
(0.00 \mathrm{I})\end{array}$ & $\begin{array}{l}0.33 \\
(0.09)\end{array}$ \\
\hline MCP-I & $\begin{array}{l}0.28 \\
(0.32)\end{array}$ & $\begin{array}{l}-0.27 \\
(0.32)\end{array}$ & $\begin{array}{l}-0.17 \\
(0.55)\end{array}$ & $\begin{array}{l}0.23 \\
(0.42)\end{array}$ & $\begin{array}{l}-0.36 \\
(0.19)\end{array}$ & $\begin{array}{l}0.03 \\
(0.92)\end{array}$ & $\begin{array}{l}0.01 \\
(0.96)\end{array}$ & $\begin{array}{l}0.19 \\
(0.51)\end{array}$ & $\begin{array}{l}0.77^{*} \\
(0.001)\end{array}$ & & $\begin{array}{l}0.32 \\
(0.10)\end{array}$ \\
\hline VEGF-A & $\begin{array}{l}0.23 \\
(0.42)\end{array}$ & $\begin{array}{l}0.18 \\
(0.52)\end{array}$ & $\begin{array}{l}0.20 \\
(0.48)\end{array}$ & $\begin{array}{l}0.23 \\
(0.4 I)\end{array}$ & $\begin{array}{l}-0.04 \\
(0.88)\end{array}$ & $\begin{array}{l}0.34 \\
(0.22)\end{array}$ & $\begin{array}{l}0.21 \\
(0.46)\end{array}$ & $\begin{array}{l}0.31 \\
(0.25)\end{array}$ & $\begin{array}{l}0.68^{*} \\
(0.01)\end{array}$ & $\begin{array}{l}0.68^{*} \\
(0.006)\end{array}$ & \\
\hline
\end{tabular}

Notes: Objective VA (logMAR) and SD-OCT values are correlated among each other and with the values of the vitreal cytokines. The results are represented with correlation coefficient $r$ and $P$-values in brackets; *statistically significant correlations.

Abbreviations: BRVO, branch retinal vein occlusion; CMT, central macular thickness; Cysts, intraretinal cysts; dEL, disruption of the inner and outer photoreceptor segments; dELM, disruption of the external limiting membrane; IL-6, interleukin-6; logMAR, logarithm of the minimum angle of resolution; MCP-I, monocyte chemoattractant protein-I; SD-OCT, spectral-domain optical coherence tomography; SRT, subfoveal serous retinal thickness; TRT, total retinal thickness; TNeuro, thickness of the neurosensory retina; VA, visual acuity; VEGF-A; vascular endothelial growth factor-A. 
Table 4 Spearman rank correlation matrix

\begin{tabular}{|c|c|c|c|c|c|c|c|c|c|c|c|}
\hline & VA & CMT & TRT & TNeuro & SRT & dEL & dELM & Cysts & IL-6 & MCP-I & VEGF-A \\
\hline \multirow[t]{2}{*}{ VA } & & $0.34^{*}$ & $0.34 *$ & $0.34 *$ & $0.48 *$ & $0.33 *$ & $0.37 *$ & $0.30 *$ & 0.31 & 0.22 & $0.42 *$ \\
\hline & & $(0.02)$ & $(0.03)$ & $(0.03)$ & $(0.002)$ & $(0.03)$ & $(0.02)$ & $(0.04)$ & $(0.45)$ & $(0.18)$ & $(0.01)$ \\
\hline \multirow[t]{2}{*}{ CMT } & & & $0.83^{*}$ & 0.24 & $0.58^{*}$ & $0.58 *$ & $0.48 *$ & $0.36^{*}$ & 0.04 & -0.09 & 0.20 \\
\hline & & & $(0.001)$ & $(0.12)$ & $(0.00 \mathrm{I})$ & $(0.001)$ & $(0.00 \mathrm{I})$ & $(0.02)$ & $(0.82)$ & $(0.55)$ & $(0.2)$ \\
\hline \multirow[t]{2}{*}{ TRT } & & & & $0.42^{*}$ & $0.61 *$ & $0.71 *$ & $0.64^{*}$ & $0.35^{*}$ & 0.05 & -0.06 & 0.27 \\
\hline & & & & $(0.005)$ & $(0.00 I)$ & $(0.001)$ & $(0.00 I)$ & $(0.02)$ & $(0.78)$ & $(0.70)$ & (0.09) \\
\hline \multirow[t]{2}{*}{ TNeuro } & & & & & 0.18 & $0.39 *$ & $0.40 *$ & $0.42 *$ & 0.14 & 0.22 & $0.31 *$ \\
\hline & & & & & $(0.24)$ & $(0.01)$ & $(0.01)$ & $(0.001)$ & $(0.38)$ & $(0.16)$ & $(0.04)$ \\
\hline \multirow[t]{2}{*}{ SRT } & & & & & & $0.66^{*}$ & $0.59 *$ & $0.30 *$ & -0.003 & -0.19 & 0.18 \\
\hline & & & & & & $(0.001)$ & $(0.00 I)$ & $(0.04)$ & $(0.85)$ & $(0.22)$ & $(0.25)$ \\
\hline \multirow[t]{2}{*}{$\mathrm{dEL}$} & & & & & & & $0.90^{*}$ & 0.23 & 0.13 & 0.02 & $0.33^{*}$ \\
\hline & & & & & & & $(0.00 I)$ & $(0.14)$ & $(0.42)$ & $(0.93)$ & $(0.03)$ \\
\hline \multirow[t]{2}{*}{ dELM } & & & & & & & & 0.19 & 0.07 & -0.05 & 0.30 \\
\hline & & & & & & & & $(0.23)$ & $(0.68)$ & $(0.73)$ & $(0.06)$ \\
\hline \multirow[t]{2}{*}{ Cysts } & & & & & & & & & 0.05 & 0.09 & 0.17 \\
\hline & & & & & & & & & $(0.76)$ & $(0.61)$ & $(0.29)$ \\
\hline \multirow[t]{2}{*}{ IL-6 } & & & & & & & & & & $0.79 *$ & $0.46^{*}$ \\
\hline & & & & & & & & & & $(0.001)$ & $(0.001)$ \\
\hline \multirow[t]{2}{*}{ MCP-I } & & & & & & & & & & & $0.42 *$ \\
\hline & & & & & & & & & & & $(0.001)$ \\
\hline
\end{tabular}

Notes: Objective VA (logMAR) and SD-OCT values are correlated among each other and with the values of the vitreal cytokines (IL-6, MCP-I, and VEGF-A). The results are represented with the correlation coefficient $r$ and $P$-values are in brackets; *statistically significant correlations.

Abbreviations: CMT, central macular thickness; Cysts, intraretinal cysts; dEL, disruption of the inner and outer photoreceptor segments; dELM, disruption of the external limiting membrane; IL-6, interleukin-6; logMAR, logarithm of the minimum angle of resolution; MCP-I, monocyte chemoattractant protein-I; SD-OCT, spectral-domain optical coherence tomography; SRT, subfoveal serous retinal thickness; TRT, total retinal thickness; TNeuro, thickness of the neurosensory retina; VA, visual acuity; VEGF-A; vascular endothelial growth factor-A.

$(\mathrm{r}=0.37, P<0.05)$. VA was analyzed with $\log$ MAR values and correlated significantly to all SD-OCT parameters (Table 4). VA and CMT $(r=0.34)$, TRT $(r=0.34)$, TNeuro $(r=0.34)$, SRT $(\mathrm{r}=0.48), \mathrm{dEL}(\mathrm{r}=0.33), \mathrm{dELM}(\mathrm{r}=0.37)$, and intraretinal cysts $(r=0.30)$ were all correlated. VEGF was the only cytokine that correlated with VA significantly $(r=0.42)$, and this was also demonstrated in the fresh BRVO subgroup $(r=0.53)$.

\section{Discussion}

Early intravitreal injections after the onset of BRVO and intact retinal layers (like ELM), as assessed by SD-OCT, are associated with a better visual outcome. ${ }^{13,14}$ In this study, we assessed the levels of inflammatory and angiogenic cytokines in the undiluted vitreous of treatment-naïve patients with $\mathrm{ME}$ secondary to nonischemic BRVO using flow cytometric BEAD array, and we correlated the results with objective clinical parameters, such as BRVO-associated changes in SD-OCT.

Recent studies with SD-OCT have shown that ME secondary to BRVO is often characterized by numerous cystoid spaces and marked retinal swelling, especially in the outer retinal layers. ${ }^{15,16}$ We are not aware of any correlation of SD-OCT parameters with intraocular cytokine levels published to date. In our study, VEGF-A was the only cytokine to positively correlate significantly with two SD-OCT parameters (TNeuro and dEL). Tsujikawa et $\mathrm{al}^{3}$ previously described the importance of the integrity of the EL as a landmark for good VA. Interestingly, we could demonstrate that elevated VEGF was associated with the disruption of the EL junction and the thickness of the neurosensory retina. VEGF was the only cytokine that also correlated with VA. As this finding was pronounced in the fresh BRVO subgroup, we speculate that the ME in the acute phase may be predominated by the barrier breakdown of the vascular wall, caused by VEGF. We demonstrated higher levels for all three cytokines in the fresh BRVO subgroup compared with the old BRVO subgroup. Although MCP-1 induces VEGF-A gene expression by upregulating hypoxia-inducible factor 1 (HIF-1 alpha), we could not determine high cytokine levels in the older BRVO subgroup. ${ }^{17,18}$ Thus, it seems that VEGF and $\mathrm{MCP}-1$ are not the key cytokines during the chronic stage in older BRVO cases and that other cytokines are more appropriately examined in these cases.

Funk et $\mathrm{al}^{5}$ examined aqueous samples with CBA at baseline prior to intravitreal anti-VEGF therapy in eight patients, 10 months after the onset of nonischemic BRVO. The IL-6 $(\Delta=-2 \mathrm{pg} / \mathrm{mL}), \operatorname{MCP}-1(\Delta=-83 \mathrm{pg} / \mathrm{mL})$, and VEGF levels $(\Delta=-40 \mathrm{pg} / \mathrm{mL})$ were all lower than in our study. However, it is questionable whether the aqueous 
samples and low number of patients can be compared with our study results in BRVO, as we strive to understand more about this original retinal disease.

The limitations of our study are the small sample size, which may have to be taken into consideration, especially when interpreting the ischemic BRVO group significant differences.

The concept of our study was to provide evidence about cytokines and their correlation to SD-OCT changes in the undiluted vitreous of patients suffering from a condition other than vitreomacular traction or other clinical state that would have qualified for a complete three-port vitrectomy (as in the studies by Noma et al). ${ }^{10,15,16}$

In conclusion, we demonstrated significantly higher values of inflammatory and proangiogenic cytokines in eyes with "fresh," treatment-naïve BRVO compared with control eyes. The cytokines highly correlated with one another. VEGF-A was partly correlated with the morphologic changes assessed by SD-OCT, whereas the inflammatory markers had no significant influence on SD-OCT changes. The morphological changes detected in SD-OCT may in the future, become more clinically relevant with a direct biofeedback mechanism, like the vitreal load of dysregulated cytokines.

\section{Acknowledgments}

The research group is supported by The Adolf Messer Foundation, Königstein, Germany; Dr. Werner JackstädtStiftung, Wuppertal, Germany.

\section{Disclosure}

The authors report no conflicts of interest in this work.

\section{References}

1. Spaide RF, Curcio CA. Anatomical correlates to the bands seen in the outer retina by optical coherence tomography: literature review and model. Retina. 2011;31(8):1609-1619.

2. Shin HJ, Chung H, Kim HC. Association between integrity of foveal photoreceptor layer and visual outcome in retinal vein occlusion. Acta Ophthalmol. 2011;89(1):e35-e40.
3. Tsujikawa A, Sakamoto A, Ota M, et al. Serous retinal detachment associated with retinal vein occlusion. Am J Ophthalmol. 2010;149(2): 291-301.

4. Kriechbaum K, Prager F, Geitzenauer W, et al. Association of retinal sensitivity and morphology during antiangiogenic treatment of retinal vein occlusion over one year. Ophthalmology. 2009;116(12): 2415-2421.

5. Funk M, Kriechbaum K, Prager F, et al. Intraocular concentrations of growth factors and cytokines in retinal vein occlusion and the effect of therapy with bevacizumab. Invest Ophthalmol Vis Sci. 2009;50(3): 1025-1032.

6. Jo N, Wu GS, Rao NA. Upregulation of chemokine expression in the retinal vasculature in ischemia-reperfusion injury. Invest Ophthalmol Vis Sci. 2003;44(9):4054-4060.

7. Ryan SJ, editor. Retina. Philadelphia, PA: Mosby; 2006:2645.

8. Pe'er J, Folberg R, Itin A, Gnessin H, Hemo I, Keshet E. Vascular endothelial growth factor upregulation in human central retinal vein occlusion. Ophthalmology. 1998;105(3):412-416.

9. Cohen T, Nahari D, Cerem LW, Neufeld G, Levi BZ. Interleukin 6 induces the expression of vascular endothelial growth factor. $\mathrm{J} \mathrm{Biol}$ Chem. 1996;271(2):736-741.

10. Noma H, Funatsu H, Mimura T, Eguchi S, Shimada K, Hori S. Vitreous levels of pigment epithelium-derived factor and vascular endothelial growth factor in macular edema with central retinal vein occlusion. Curr Eye Res. 2011;36(3):256-263.

11. Koss MJ, Pfister M, Rothweiler F, et al. Comparison of cytokine levels from undiluted vitreous of untreated patients with retinal vein occlusion. Acta Ophthalmol. 2012;90(2):e98-e103.

12. Koss MJ, Naser H, Sener A, et al. Combination therapy in diabetic macular oedema and retinal vein occlusion - past and present. Acta Ophthalmol. 2012;90(6):580-589.

13. Haller JA, Bandello F, Belfort R Jr, et al; OZURDEX GENEVA Study Group. Randomized, sham-controlled trial of dexamethasone intravitreal implant in patients with macular edema due to retinal vein occlusion. Ophthalmology. 2010;117(6):1134-1146.

14. Wolf-Schnurrbusch UE, Ghanem R, Rothenbuehler SP, Enzmann V, Framme C, Wolf S. Predictors for short-term visual outcome after antiVEGF therapy of macular edema due to central retinal vein occlusion. Invest Ophthalmol Vis Sci. 2011;52(6):3334-3337.

15. Noma H, Funatsu H, Mimura T, Eguchi S, Shimada K. Inflammatory factors in major and macular branch retinal vein occlusion. Ophthalmologica. 2012;227(3):146-152.

16. Noma H, Funatsu H, Mimura T, Eguchi S. Vascular endothelial growth factor receptor-2 in macular oedema with retinal vein occlusion. Ophthalmic Res. 2012;48(1):56-58.

17. Schober A, Zernecke A. Chemokines in vascular remodeling. Thromb Haemost. 2007;97(5):730-737.

18. Hong KH, Ryu J, Han KH. Monocyte chemoattractant protein-1-induced angiogenesis is mediated by vascular endothelial growth factor-A. Blood. 2005;105(4):1405-1407.
Clinical Ophthalmology

\section{Publish your work in this journal}

Clinical Ophthalmology is an international, peer-reviewed journal covering all subspecialties within ophthalmology. Key topics include: Optometry; Visual science; Pharmacology and drug therapy in eye diseases; Basic Sciences; Primary and Secondary eye care; Patien Safety and Quality of Care Improvements. This journal is indexed on

\section{Dovepress}

PubMed Central and CAS, and is the official journal of The Society of Clinical Ophthalmology (SCO). The manuscript management system is completely online and includes a very quick and fair peer-review system, which is all easy to use. Visit http://www.dovepress.com/ testimonials.php to read real quotes from published authors. 